\title{
Participatory scenarios as a tool to link science and policy on food security under climate change in East Africa
}

\author{
Moushumi Chaudhury $\cdot$ Joost Vervoort • \\ Patti Kristjanson · Polly Ericksen · Andrew Ainslie
}

Received: 15 December 2011 / Accepted: 9 September 2012/Published online: 22 September 2012

(C) The Author(s) 2012. This article is published with open access at Springerlink.com

\begin{abstract}
How effective are multi-stakeholder scenariosbuilding processes to bring diverse actors together and create a policy-making tool to support sustainable development and promote food security in the developing world under climate change? The effectiveness of a participatory scenario development process highlights the importance of "boundary work" that links actors and organizations involved in generating knowledge on the one hand, and practitioners and policymakers who take actions based on that knowledge on the other. This study reports on the application of criteria for effective boundary work to a multi-stakeholder scenarios process in East Africa that brought together a range of regional agriculture and food systems actors. This analysis has enabled us to evaluate the extent to which these scenarios were seen by the different actors as credible, legitimate and salient, and thus more likely to be useful. The analysis has shown gaps and opportunities for improvement on these criteria, such as the quantification of scenarios, attention to translating and communicating the results through various channels and new approaches to enable a more inclusive and diverse group of participants. We conclude that applying boundary work criteria to multi-stakeholder scenarios processes can do much to increase the likelihood of developing
\end{abstract}

M. Chaudhury $(\bowtie) \cdot$ P. Kristjanson

CGIAR Research Program on Climate Change, Agriculture, and Food Security (CCAFS), Nairobi, Kenya

e-mail: M.Chaudhury@cgiar.org

J. Vervoort

University of Oxford, Oxford, UK

P. Ericksen

International Livestock Research Institute, Nairobi, Kenya

A. Ainslie

Oxford Brookes University, Oxford, UK sustainable development and food security policies that are more appropriate.

Keywords Multi-stakeholder scenarios · Boundary work · Credibility $\cdot$ Salience $\cdot$ Legitimacy $\cdot$ Capacity building · East Africa

\section{Introduction}

Complex global issues like rising food prices, a changing climate, and predictions that a $70 \%$ increase in food production will be needed by 2050 to feed the earth's projected 9 billion people (FAO 2009) require new initiatives that bring people together across a broad spectrum of sectors and disciplines to explore innovative ideas and devise potential solutions. Representatives from farmers' organizations, scientists, policymakers, civil society, government and the private sector all have important roles to play in formulating new policies for improved food systems as we enter an increasingly uncertain future.

Bringing diverse communities into constructive dialogue aimed at addressing complex problems requires rigorous, yet flexible processes (Henrichs et al. 2010; Lucas et al. 2010). This type of work is important because it: (1) encourages and provides space for multiple perspectives to be aired and considered, (2) allows different perspectives to be captured in policies and (3) facilitates acceptance of policies as co-constructed and thus as legitimate and relevant to more people and constituencies. Such processes are only beginning to be applied to food systems in the developing world (Kristjanson et al. 2009), where populations face high vulnerability to global environmental change and increasing food insecurity, both of which require urgent action (Ericksen 2008). 
An initiative led by the global research program on Climate Change, Agriculture and Food Security (CCAFS) is focused on ways to promote 'climate-smart' agriculture and food security (Vermeulen et al. 2011). This program links research for development work in 15 international agricultural research centers with the global environmental change research community. A key objective of CCAFS is to develop and test approaches that enhance the likelihood that knowledge generated by the program's partners will lead to actions (changes in policies, practices, technologies) that improve food security in an environmentally sustainable manner (Vermeulen et al. 2010).

One such 'linking knowledge with action' approach being tested by CCAFS is the participatory development of regional multi-stakeholder scenarios. The first of these scenarios describes plausible future development pathways for food systems, environments and livelihoods in East Africa under different assumptions about likely directions of regional environmental and socio-economic change. While the initial approach has been qualitative, modeling is underway to quantify and test the viability of various strategies and policy options. The scenarios will be debated and refined in a process of continuous strategic learning between stakeholders in the region. The CCAFS scenarios development process aims to span knowledge and other boundaries across a diverse range of actors and organizations to facilitate concerted action for improved food security, environments and livelihoods. This paper assesses the effectiveness of the scenario process in bridging boundaries.

We draw on the expanding body of research on "boundary work" (Clark et al. 2010, 2011) to assess the utility of the process of developing and using scenarios in East Africa for bridging science and non-science boundaries and linking knowledge with action. This involves an assessment of the extent to which the process of building scenarios has been credible, salient, legitimate (Cash et al. 2003) and has built capacity among participants across knowledge boundaries. Because our interest here is to evaluate the effectiveness of the engagement process, this paper does not address technical scenario issues, such as identifying key drivers and variables. Instead, it focuses on an area that has not been well researched to date-the ability of multi-stakeholder scenarios processes to bridge science and non-science boundaries at a regional level.

\section{Boundary work and its relevance to scenario development}

"Boundary work" aims to assess the extent to which scientific knowledge can be translated into something tangible and useful for decision makers formulating new policies, rules and regulations (Clark et al. 2010). Narrowly defined, it attempts to span the divide that often exists between science and non-science disciplines and sectors (Guston 2001; Jasanoff 1996). More broadly, boundary work can be facilitated by organizations or individuals that act as "knowledge brokers", encouraging full participation by people from various disciplines and backgrounds, helping them to communicate with each other and jointly design problem-solving actions. These "boundary organizations" help keep information flowing between knowledge producers and users, while promoting mutual respect and trust (Cash et al. 2003). They integrate perspectives and insights from different disciplines and set up the incentives and a safe environment for the joint creation of 'boundary products' such as assessment reports, articles, brief, maps, scenarios or other products (e.g., ideas and models jointly conceived and produced) (Reid et al. 2009). Successful boundary organizations and products are 'adaptable to different viewpoints and robust enough to maintain identity across them' (Cash et al. 2003, p. 8089). Cash et al. (2006) propose that boundary work can do much to bridge divides and mismatches between different system levels on and across spatial, jurisdictional and/or ecological scales.

Cash et al. (2003) describe the main principles that underpin successful boundary work. First, credibility-the perceived technical quality or adequacy of technical evidence and arguments_-needs to be established. This involves establishing whether the information contributed in participants' dialogue is valid, accurate, tested and viewed by those from different science or non-science backgrounds, for example, to be not only 'true' (that is, based on rational, empirical evidence), but also up-to-date and cutting-edge in each of their respective disciplines and professional experiences. Second, salience-the perceived relevance of the technical information provided to decision makers-is critical. This entails assessing whether information provided is needed by those taking actions on it, and in a form that is understandable and can be used in a timely manner. Third, the legitimacy of the process of generating the information and perspectives is an important consideration - is the process viewed by all as fair, inclusive and unbiased? This involves analyzing who participated in producing the knowledge, how they were selected, how they were engaged, levels of collaboration, and how the agenda for the dialogue was proposed, negotiated and set.

Cash et al. suggest that establishing credibility, saliency and legitimacy requires good communication, translation and mediation efforts. In common with other processes aimed at building progressive coalitions for societal and environmental change, open communication in the process of boundary work can lead to the 'democratization of science' by a heterogeneous group of people (Jasanoff 2003). 
In the process, various participants are enabled to express their views and see those views incorporated into larger decision-making processes. This can also empower groups that may not have the opportunity to participate in these types of debates and knowledge-generation projects (Leach and Scoones 2006). Van Noordwijk et al. (2001), however, point out that to be effective, more than just good communication is needed. They developed and applied a negotiation support model, where researchers, communities and development workers engaged in systematic and continuous negotiations to jointly address and solve conflicts and natural resource management challenges.

Boundary work may also produce "standardized packages" considered to be more "robust" than boundary objects because they lead to changes in practices on both sides of the boundary (Fujimura 1992, cited in Guston 2001). In our case, many actors are co-creating and learning about plausible futures and possible adaptation strategies together in the scenario development process. We will continue to track the extent to which behaviors and practices actually change as a result.

If the boundary work that links agricultural research knowledge with sustainable poverty reduction actions rests on better communication, translation and mediation efforts, then capacity strengthening is crucial to the success of these efforts (Kristjanson et al. 2009). Building capacity to interpret scientific evidence by a non-science audience assists in the momentum-building processes required to move from scientific research into effective policy (Jones et al. 2008). It is equally important to build the communication capacities of scientists to engage with decision and policy makers by improving scientists' understanding of the policy process and policy audience's knowledge needs (Scott 2006 cited in Jones et al. 2008). This can be done through boundary work that is integrated into the scenario development process that brings scientists and their diverse audiences, including policy makers, into sustained dialogue.

\section{Scenarios approaches}

Scenarios are descriptions of possible futures that reflect different perspectives on past, present and future developments (van Notten 2003). Unlike predictions, projections and forecasts, scenarios portray alternate futures that are considered plausible but do not claim to offer any certainty about future developments, instead recognizing the uncertainty inherent in a complex world (Van Notten et al. 2005; Wilkinson and Eidinow 2008). Scenarios are designed to offer holistic, integrative and multi-dimensional perspectives on these plausible futures (Xiang and Clarke 2003). Both within organizations and in multi-stakeholder contexts, scenarios provide an alternative to planning and modeling based on a forecasting paradigm (Rotmans et al. 2000). Scenarios help focus on complexity and uncertainty in human and natural systems and are often most useful in situations of high uncertainty and considerable ignorance about causality constraining action to resolve problems (Gallopin 2002). Scenarios can help organizations and multi-stakeholder groups "shift strategy, at the organizational level, from notions of competition and the search for equilibrium and adaptation to strategy as continuous change, a search for emergence and improvisation and collaboration" (Selsky and McCann 2008 cited in Wilkinson and Eidinow 2008: 4).

To frame the scenarios development process used by CCAFS within the wider practice of scenarios development, we follow Wilkinson and Eidinow (2008), who distinguish two main types of scenarios processes used in the context of exploring environmental issues:

- Problem-oriented scenarios development. This type of scenarios process is aimed at reducing future uncertainties. An underlying assumption in this type of process is that scientific accuracy is key in scenarios of the future. Scenarios in this type of process are the result of generated knowledge rather than the scenarios process itself generating such knowledge.

- Actor-oriented scenarios development. This type of scenarios process uses scenarios development as a learning process that focuses on 'thinking the unthinkable' (Kahn and Wiener 1967) in which unprecedented insights can emerge. It seeks not to reduce but to acknowledge uncertainty and the possibility for radical, unexpected and discontinuous change. It has largely been used in single-organization contexts to explore the environment in which an organization has to adapt and act (Schwartz 1991). This type of process focuses on harnessing the intuitive logics of an interdisciplinary assembly of participants and works mainly with qualitative information.

When scenarios are used within an organization, a variety of actor-centered scenarios processes have often been used (Schwartz 1991). Partly because of the higher need for credibility that exists in inter-organizational contexts and to make scenarios more useful to a range of users, this qualitative, creativity-oriented approach has also been combined with the use of quantitative methods such as modeling (Kok and van Delden 2004).

When scenarios are used in multi-stakeholder contexts, they have a number of additional functions and benefits. They allow for the sharing and linking of fundamentally different analytic and experiential perspectives. In this, they are able to draw upon a wide range of knowledge types that allow those involved to better explore a range of 
possible futures (Rotmans et al. 2000). They also show potential to generate mutual understanding and appreciation of other perspectives. Going a step beyond these potential benefits, scenarios can offer a platform for generating new relationships and networks, commitments and actionable ideas (Kahane 2010).

Wilkinson and Eidinow (2008) propose a third type of scenarios process that encapsulates and extends this potential and provides a theoretical frame for a more comprehensive and transformative scenarios approach, called the 'reflexive interventionist multi-actor' (RIMA) approach. RIMA is aimed specifically at multi-stakeholder contexts and 'wicked problems' (Rittel and Webber 1973), where problem boundaries and ownership are complex, dynamic and unclear. Potential solutions can lead to, or uncover, more complex problems. Here, complexity is not just methodological but also ethical—and conflicting purposes are at play. RIMA advocates an iterative, non-linear and reflexive process that recognizes and uses its role in shaping the environment being explored, the actors involved, and itself. One of its aims is to change the way participants think about the future and how it relates to the past and to the present. Another feature that differentiates RIMA from the previous two types of scenario processes is that its aim is not simply for more participation, but more effective participation. This is built on an explicit recognition of the need for truly different perspectives and world views which can, at any time, challenge limiting paradigms that may arise and dominate the process. Wilkinson and Eidinow (2008) argue that RIMA is a formalization of what actually already happens when futures are considered by a range of actors. Thus, it is not so much a new type of scenarios process as a conscious recognition and harnessing of the realities of collaborative futures work.

\section{The CCAFS scenarios initiative as boundary work}

\section{Regional focus}

CCAFS has, for a number of reasons, taken an explicitly regional approach to its scenario-building work. According to Liverman and Ingram (2010), regional scenarios offer an understanding of environmental change at larger scales that encompass biophysical classifications, such as river basins, which are integral to East Africa. Agro-ecological zones are mapped onto regions because of common physical characteristics that cross national (i.e., country) boundaries. Climate and weather perturbations frequently have impacts at the regional level. In addition to biophysical similarities, regions may share certain cultural similarities, so that similar language, relatively integrated economies and related social practices, such as food habits and preferences are embedded in the functioning of food systems. Intraregional trade is an important factor in understanding food security since it can either enhance or hinder food security depending on the nature of, for example, the management of regional strategic food reserves and the development and maintenance of transport infrastructure and food processing facilities. Thus, the principle of working at the regional scale makes sense. But what does this mean for developing scenarios that are credible, salient and legitimate?

In the concept development stage, the key regional organizations, the Association for Strengthening Agricultural Research in Eastern and Central Africa (ASARECA) and the IGAD Climate Prediction and Applications Centre (ICPAC) were identified as the most likely clients (users) of the outputs of the scenario development process. In opting to work at the regional level, CCAFS took into account the country membership of these East Africanbased partner organizations and took Ethiopia, Kenya, Tanzania and Uganda as the initial East Africa region in the CCAFS scenario-building exercise. The CCAFS scenarios process in East Africa has taken its initial cues from the actor-centered type of scenarios process and, as the process progresses, from the RIMA approach.

\section{Actor-centered scenarios and summary of the scenarios}

In the CCAFS East Africa scenarios process, participatory, multi-stakeholder scenarios focused initially on exploring alternative futures through the harnessing of a range of perspectives from different disciplines and sectors. Figure 1 below shows the different steps taken and reflects the need to build credibility, salience, legitimacy and capacity building into the scenarios development process. The first two steps involved three scenarios development workshops that followed an actor-centered scenarios approach. A concern for the legitimacy of the process guided the selection of a diverse group of stakeholders so that different perspectives were sought. These were carefully integrated, with a view to enhancing the credibility, as well as the richness and salience of the scenarios. The relevance of the process rested on including as many and as diverse a network of potential scenarios users in the process as was practicable. Scenario development practitioners helped guide the process and aimed to strengthen the capacity of all participants to collaboratively develop the qualitative scenarios.

The questionnaire administered to the participants after the third workshop forms the basis of this review of the boundary work of the scenarios in these initial steps. The responses to the questionnaire provide evidence of the extent to which CCAFS's scenarios-building process was perceived by this wide range of actors to be credible, salient and legitimate and to have built capacity in East Africa to use such forward-looking processes to improve 


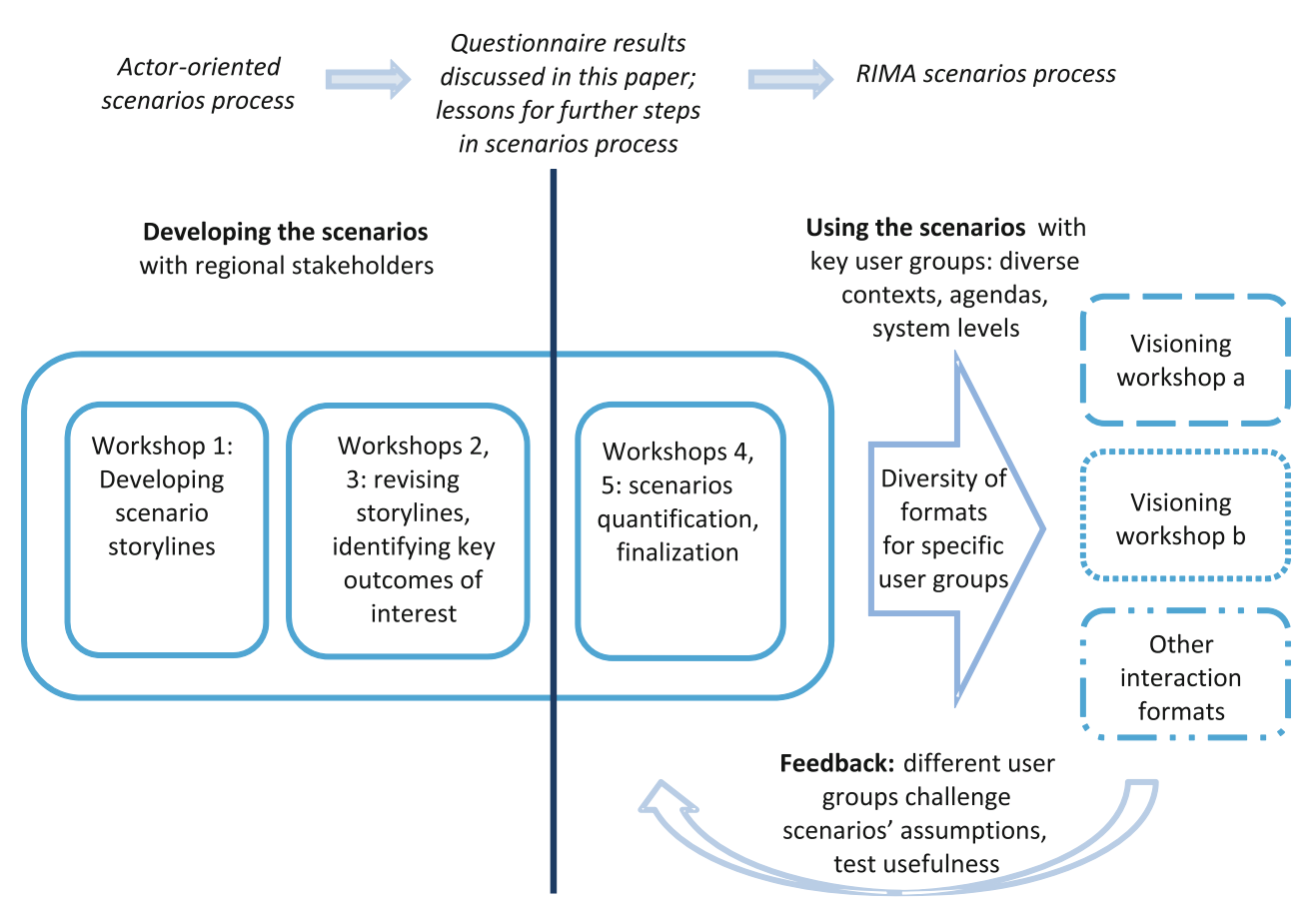

Fig. 1 CCAFS scenarios process in East Africa

decision making in achieving food security. Based on our analysis of these data, current and future steps have been revised, and we have taken cues from the RIMA model to increase the impacts of the scenarios development process throughout the region.

This 'action learning' strategy aligns with actor-centered scenarios in the typology used in this paper. Our explicit aim was to use scenarios to create a space for the development of shared insights and the enabling of a strategic conversation (van der Heijden 1996) about multi-dimensional, complex issues (the relationships, trade-offs and synergies between food security, environments and livelihoods). The creation of this shared space makes the actor-centered type of scenarios process very suitable for boundary work because it is set up to facilitate mutual understanding, the creation and sustenance of new networks and a shared purpose across boundaries of discipline, sector and national jurisdiction. As with the actor-centered approach, a diversity of perspectives was acknowledged as important. We aimed to invite participants from different countries and a wide range of disciplinary backgrounds and sectors to the workshops. The focus was not only on explicitly eliciting these different perspectives, but also creating a shared understanding and a dialogue across system boundaries.

Three regional workshops (numbered 1, 2 and 3) were organized in which participatory, multi-stakeholder scenarios were progressively developed. The actor-oriented process started with identifying drivers of change, which includes both important and highly uncertain, as well as important and less uncertain drivers. Important and highly uncertain drivers in East Africa are the extent of regional integration (both political and economic); and the proactive/ reactive stance of governments (and other regional stakeholders) at the regional level in relation to environmental management and food security. These key uncertainties determine the focus of the different scenarios. Figure 2 below illustrates the two-axes schema, developed to think about the drivers of change in the East African system.

Storylines were developed for each of the four scenarios created by the two axes of uncertainty. Table 1 provides a brief description of these storylines that gives a sense of their relevance for the governance of food systems, environmental management and development of livelihoods across sectors.

Based on these storylines, the workshop group determined a number of common outcomes of interest for food security, environment and livelihoods and examined which factors would contribute to these outcomes. The 13 outcomes of interest include food affordability, regional production, food distribution and nutritional value for food security; water quality, soil quality, forest cover, biodiversity status and water sufficiency for environment; and financial wealth, social capital, health and knowledge and skills for livelihoods.

Evaluation of credibility, salience, legitimacy and capacity building within an actor-centered approach

The process and progress of the scenario-building exercises in East Africa were evaluated by participants after each of 


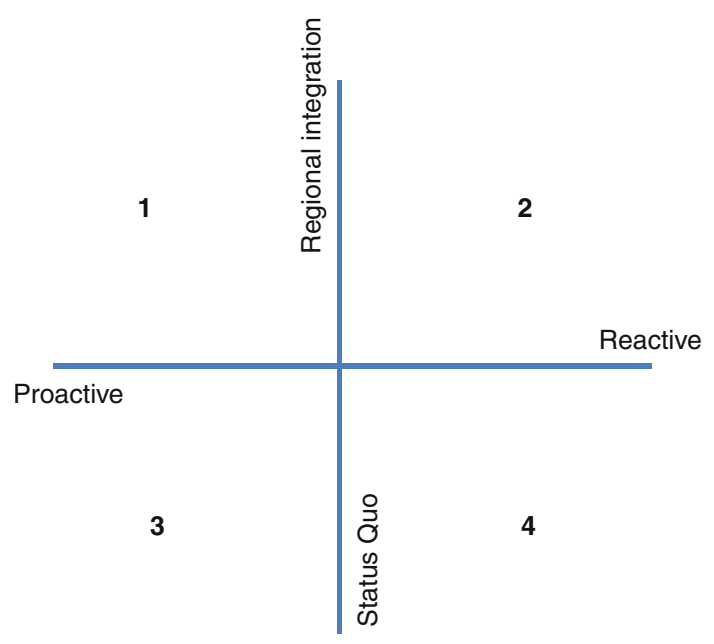

Fig. 2 The 'two-axis' schema for drivers in East Africa to 2030

the first two workshops. This included an assessment of the level of engagement, interest and learning in the process of boundary work and scenario building. Although these post workshop evaluations provided important insights into the process, the initial evaluations were not framed specifically in terms of assessing credibility, salience, legitimacy and capacity building. To address these issues specifically, a structured questionnaire (see Table 2) based on these concepts of boundary work was developed.

The questionnaire was completed by 14 of the 17 participants and or key storyline writers involved throughout the process.

\section{Credibility}

The concept of credibility as a requisite for boundary work refers to the perceived quality of the sources of knowledge for the content developed by different audiences and users
(Cash et al. 2003). In multi-stakeholder scenarios, participants may include both the producers and users of knowledge. Workshop participants can be categorized into four types (Huitema and Turnhout 2009; Jones et al. 2008), including networks (e.g., farmers organizations, the private sector), epistemic communities (e.g., agriculture research institutes and meteorological offices), policy communities (national and regional policy makers, donors) and advocacy coalitions (e.g., NGOs). Endeavors to consciously select participants from this range of interest group and expertise were driven by the multi-faceted nature of climate change, agriculture and food security in East Africa.

Table 3 below shows the distribution of the type of stakeholders that were involved in the first and second workshops, held in August and November 2010 respectively.

The distribution of the type of participants suggests that the scenario-building process was initially heavily biased toward epistemic communities (specifically researchers active in the agricultural sector), since on average, $56 \%$ of participants belonged to this category. In order to assess the perceived credibility of the scenarios, scenario writers were asked to assess the diversity of backgrounds of those participating. All respondents stated that several key stakeholders were missing, specifically policy makers, civil society representatives, social scientists, ecologists, farmers and private sector representatives.

Half (fifty percent) of the respondents, however, thought that although certain stakeholder groups were missing, those who attended were experts in their fields, and therefore, there was sufficient knowledge and adequate discussion on East African issues to make the scenarios credible. For instance, one respondent stated "[the process] has shown me a new way of planning for the future. As an advisor and coordinator on the livestock feed resources, [the process] has added substantial knowledge and widened

Table 1 Brief description of East Africa scenarios

\begin{tabular}{lc}
\hline Scenario & Essential features \\
\hline $\begin{array}{l}\text { Regional integration and } \\
\text { proactive }\end{array}$ & $\begin{array}{c}\text { Political stability and major investment in regional infrastructure and telecommunications has led to sustained } \\
\text { economic growth. Governments have focussed on improving food security and reducing poverty, but pastoralists, } \\
\text { small-scale farmers and fishers have been marginalized. Already-agreed afforestation program has finally been } \\
\text { implemented, and regional water resource management has improved }\end{array}$ \\
$\begin{array}{c}\text { Regional integration and } \\
\text { reactive }\end{array}$ & $\begin{array}{l}\text { Regional economic and political integration has realized substantial gains and trade is booming in the region. } \\
\text { However, the region is only reactive to shocks, so growth has been at expense of the environment and food } \\
\text { status quo and proactive } \\
\text { The competitive interests of individual states prevail at the expense of the region. Excellent progress has been } \\
\text { made in managing the region's water resources, underwritten by donors. Some growth has been the norm, yet } \\
\text { progress on poverty reduction has been slow. Civil society and NGOs are filling many of the gaps created by } \\
\text { weak states } \\
\text { Poor governance, lack of integration, fragile political environments and exposure to waves of globalization to } \\
\text { 2030; limited planning of interventions for addressing poverty, food insecurity, livelihood diversification, } \\
\text { markets access and environmental degradation. Political instability means population growth leads to conflicts } \\
\text { around water }\end{array}$ \\
\hline
\end{tabular}


Table 2 Sample of questions from the scenario questionnaire

\begin{tabular}{|c|c|c|c|}
\hline Credibility & Salience & Legitimacy & Capacity building \\
\hline $\begin{array}{l}\text { Have there been diverse groups of } \\
\text { people who participated in the } \\
\text { scenario-building process from } \\
\text { both scientific and non-scientific } \\
\text { communities? }\end{array}$ & $\begin{array}{l}\text { Do you foresee that these storylines } \\
\text { will help you or those you work } \\
\text { with, plan for climate change } \\
\text { adaptation? Why or why not? }\end{array}$ & $\begin{array}{l}\text { Do you feel that the process } \\
\text { allowed for open participation } \\
\text { and discussion on controversial } \\
\text { or ambiguous topics between } \\
\text { various stakeholders? Why or } \\
\text { why not? }\end{array}$ & $\begin{array}{l}\text { What techniques have you } \\
\text { learned from the scenario- } \\
\text { building process so far that } \\
\text { you will in your own work in } \\
\text { the future? }\end{array}$ \\
\hline $\begin{array}{l}\text { Do you think there was sufficient } \\
\text { knowledge and expertise among } \\
\text { the participants, and they were } \\
\text { able to provide evidence and } \\
\text { share experiences in addressing } \\
\text { issues of climate change, } \\
\text { agriculture and food security? } \\
\text { Are there any issues that were } \\
\text { missed or insufficiently } \\
\text { addressed? }\end{array}$ & $\begin{array}{l}\text { Do you feel that the scenario- } \\
\text { building process has helped you } \\
\text { gain a better understanding of } \\
\text { plausible development futures } \\
\text { and pathways within your region } \\
\text { from different perspectives? Why } \\
\text { or why not? }\end{array}$ & $\begin{array}{l}\text { Have the workshop facilitators } \\
\text { helped to translate and make } \\
\text { different jargon or experiences } \\
\text { more understandable? }\end{array}$ & $\begin{array}{l}\text { Has the process helped you } \\
\text { think about adaptive } \\
\text { capacity within the region? }\end{array}$ \\
\hline $\begin{array}{l}\text { How easy was it to understand the } \\
\text { methods used to develop the } \\
\text { scenarios with regard to } \\
\text { identifying drivers and variables? }\end{array}$ & $\begin{array}{l}\text { Are the storylines presented in a } \\
\text { manner thus far that would make } \\
\text { it easy for policy makers to } \\
\text { understand the four different } \\
\text { types of scenarios? Why or why } \\
\text { not? }\end{array}$ & $\begin{array}{l}\text { Have there been any conflicts } \\
\text { during discussion? If so, did the } \\
\text { workshop facilitators help to } \\
\text { mediate the conflict to restore } \\
\text { open communication and } \\
\text { participation, and how effective } \\
\text { (or not) was this? }\end{array}$ & \\
\hline
\end{tabular}

Table 3 Distribution of stakeholders

\begin{tabular}{llll}
\hline $\begin{array}{l}\text { Stakeholder } \\
\text { category }\end{array}$ & $\begin{array}{l}\text { August 2010- } \\
\text { stakeholder } \\
\text { proportion (\%) }\end{array}$ & $\begin{array}{l}\text { November 2010- } \\
\text { stakeholder } \\
\text { proportion }(\%)\end{array}$ & $\begin{array}{l}\text { Average } \\
(\%)\end{array}$ \\
\hline $\begin{array}{c}\text { Epistemic } \\
\text { communities }\end{array}$ & 49 & 63 & 56 \\
$\begin{array}{c}\text { Policy } \\
\text { communities }\end{array}$ & 44 & 30 & 37 \\
$\begin{array}{c}\text { Networks } \\
\begin{array}{c}\text { Advocacy } \\
\text { coalitions }\end{array}\end{array}$ & 0 & 0 & 0 \\
\hline
\end{tabular}

my thinking toward planning for future in that field." The other half of the respondents felt that knowledge, and therefore, adequate discussion was compromised due to the lack of typological diversity among participants. For instance, issues such as fisheries and biodiversity were not addressed. Despite the different views on the ability of participants to contribute knowledge and adequately discuss issues, all workshop participants agreed that the discussions were interactive, open, transparent and "rigorous" and participants "sometimes agreed to disagree". The space for open discussion and debate led $79 \%$ of the respondents to state that the scenarios represent a balanced view and no one perspective dominated.

Another factor influencing perceived credibility is the degree to which participants fully understand the process of scenario development. Fifty-seven percent of respondents felt that the scenarios process became easier to engage with over time as their level of understanding grew with each successive step in the process. Because many respondents now understood the scenario development process, $93 \%$ of the respondents stated that they envisioned using the scenario process and methods in their own work. For instance, respondents stated that they have engaged in other scenario processes after the CCAFS workshops as they have found them useful for planning of their own future work, such as in the field of famine and early warning systems.

\section{Salience}

In order to assess the salience, or the perceived relevance of the technical information discussed during the workshop, the respondents were asked whether they were likely to use the scenarios as a decision-making tool. Seventy-one percent of the respondents stated that scenarios would be a useful policy-making tool because scenarios generate contrasting yet plausible situations and options that decision makers like to see. One respondent stated "The developed storylines were good with rich room for information and it surely represented the East Africa region. The resultant storylines gave an impression that adaptation was not an option [but a necessity] and stakeholders must plan for it no matter the level [of climate change]. So the storylines are key and need to be communicated." Seventyeight percent of the participants also found the scenarios relevant as an aid to reflect on regional experiences, helping them to distinguish between terms such as "predictions" and "plausible" futures. One respondent was 
inspired enough to take a course in scenario development during his doctoral studies.

The relevance of scenarios is also dependent on how they are put together, "packaged" and presented to decision makers. One-half of respondents felt that the scenarios, in their current form, were useful as they use non-technical language more suited for policy makers. The remainder thought the relevance would be enhanced significantly by adding more quantitative information. This split with respect to the perceived relevance of the scenarios suggests that developing scenarios not only takes time because it is a learning process, but also because of the multiple tasks involved in actually bridging science/ non-science, national/regional and practitioner/policymaker boundaries and audiences.

\section{Legitimacy}

Workshop participants were asked whether they felt that the process was fair, inclusive and unbiased (that is, legitimate). Ninety-three percent of the respondents thought the process of scenario development was fair and unbiased in large part due to open and transparent discussions during the workshop. As one respondent stated, "The process has so far allowed open participation and discussion on all issues related to climate change. The discussion atmosphere was free and all participants were encouraged to give their views freely. The workshops have been free of 'fixed agenda'." This indicates that the workshop facilitators, acting as knowledge brokers, were able to foster 'safe spaces' (Kristjanson et al. 2009) and contribute to the dialogue needed to help build bridges between science and non-science constituencies. According to $86 \%$ of the respondents, the facilitators played a key role in translating jargon so that the process and methods were better understood. Respondents mentioned that there were times when the discussions would become heated, but the facilitators minimized potential conflicts by ensuring that all viewpoints were heard. Because facilitators in the workshops were CCAFS staff who had expertise in scenario development and/or technical backgrounds in food security, livelihoods and environmental governance, they were able to weed out or translate jargon while also guiding participants toward a shared understanding of the methods of scenarios development.

\section{Capacity building}

One of the major objectives of the scenario-building exercise is to build capacity within the region for participants to be able to learn how to develop, integrate, interpret, communicate and use the outputs from the scenarios process to inform policies and actions, especially in the context of climate change. Seventy-nine percent of the respondents reported having learned new skills, such as how to identify drivers of change, and how to develop storylines. One respondent stated that the difference between "forecasts" and "scenarios" as well as "projections" and "scenarios" is now clear. Methods such as stakeholder analysis and web diagram tools were particularly useful for one respondent who would now use these methods. Among those who thought their capacity to develop scenarios had increased or improved were those who reported that the process helped them to better understand: (1) the urgency of building adaptive capacity in the region; (2) concepts such as "uncertainty" and "complexity"; (3) how scenarios can be incorporated in planning for climate change-related work and developing future funding proposals; and (4) the importance of determining different adaptive capacities that exist in the region. A seasoned scenario developer who had contributed to scenario development for the Kenyan State of the Environment Report also claimed to have benefited from the process, stating "I learnt a lot from the scenario building workshops. Now it is even easy for me to understand other scenarios, e.g. the ones developed by IPCC. I gained skills on how to organize scenario building workshops, identify the drivers, narrowing down to the most important and uncertain drivers and develop story lines based on the most uncertain and important drivers."

\section{Discussion}

Based on the feedback and lessons from the first phase of the CCAFS scenarios programme in East Africa, the scenarios team instituted some changes to build on the strengths of the process to date and to overcome the weaknesses identified jointly with participants. Participants believe scenarios are a useful decision-making tool that helps link knowledge with actions, such as the development of improved policies. The process was perceived as legitimate, and the facilitators succeeded in not only providing an open and transparent space for discussion, but also helped strengthen the capacity of participants to use the knowledge generated. Based on the reported weaknesses of the process thus far, the major lessons learned and steps taken to address them are:

1. Addressing credibility through engagement with complementary networks and regional consultancies

In terms of credibility, the CCAFS scenarios process was characterized by good facilitation that allowed positive interactions, understanding and appreciation of the value of using a scenarios approach. However, a major flaw in the process in terms of credibility was the lack of participation 
from certain sectors and disciplines that were regarded as important for producing credible outputs.

We are addressing this limitation by commissioning a regional organization with scenarios experience to identify and bring on board these 'missing actors'. This means mapping key actors across sectors and disciplines in order to clearly identify all the organizational boundaries that need to be spanned (Clark et al. 2010). We are also jointly planning a number of strategic visioning workshops with different key user groups such as the East African Community, and a new CCAFS Regional Learning Platform made up of a network of regional partners across sectors. These workshops will focus on creating a shared vision between workshop participants, aligning separate goals to a common desired future. Then, the different policy options, strategies and technologies to move toward this desired future will be tested under the radically different socioeconomic and policy conditions represented within each scenario. Each of these workshops should find different benefits and flaws in the scenarios while using them, and part of the results of this next round of 'visioning' workshops will be an iterative improvement of the scenarios through sharing of user experiences.

\section{Addressing credibility and salience through quantification}

Qualitative scenario storylines offer a useful format for boundary work because storylines can integrate very different perspectives and types of information in a single story while still creating a shared understanding and integrated views between stakeholders. This gives scenarios the legitimacy needed for effective boundary work (Cash et al. 2003). However, as stand-alone results of a scenarios process, qualitative storylines may still be lacking credibility and saliency for key audiences and user groups, because they lack the confidence-building features of quantification or 'hard figures' (Alcamo 2008). For this reason, the CCAFS team engaged several experienced modeling experts to design an approach for quantifying the storylines. However, there is recognition of the fact that not all outcomes of interest can be modeled using existing data, and so social scientists and media experts will also be engaged to help quantify factors for such outcomes of interest. The quantification process requires bridging models with the storylines, as well as more general disciplinary boundaries, involving an extension of the group's shared understanding and strategic language. Initial feedback from workshop participants indicates that they believe the quantification of the scenarios will greatly enhance their usefulness, and additionally that discussions on indicators and ways to measure outcomes of interest have indeed required participants to relate to other knowledge perspectives beyond their own narrow disciplines and sectors of influence.
3. Building salience through long-term engagement with regional media networks

The value of engaging regional media experts and designers to translate the scenarios into a range of different formats to cater to different audiences became clear in the first phase. These include the use of radio programs, videos, maps, graphs, comics and theater, as well as distilling the main insights of the scenarios into simple, interactive, web-based learning models. Several of these formats will be designed and developed to allow key user groups to experiment with the scenarios in different ways which enhances bridging of science and non-science boundaries and in turn provide different types of feedback on the scenarios content. Packaging and translating key messages for different audiences will help to build salience among both developers and users of the scenarios.

\section{Conclusions}

Because the development and use of participatory, multistakeholder scenarios provides a relatively open space for strategic discussion and the joining up of different perspectives, it is potentially an excellent tool for bridging disciplinary boundaries. To be effective, this use of scenarios requires the process to be credible, legitimate, salient and focused on capacity building. The initial phase of the CCAFS actor-centered scenarios process in East Africa shows both the value of good facilitation in terms of meeting the criteria for successful boundary work and the need for the inclusion of a broad and diverse range of stakeholders. They are likely to be even more useful and used by incorporating the RIMA model that pays more explicit attention to different key perspectives, needs and aims for a long-term, reflexive and iterative co-learning process. In the CCAFS East Africa process, we are now working to harness this potential through quantification of the scenarios, collaboration with media, strategic workshops focusing on key users and mapping and engaging with a wider range of stakeholders.

CCAFS will use the same process of developing participatory, multi-stakeholder scenarios, incorporating the lessons learned from East Africa, in West Africa and South Asia. The scenarios developed through this process will be available on the CCAFS website for public use. Adding these critical elements to the process is recommended to other groups interested in setting up similar multi-stakeholder scenarios processes. We have found the concept of boundary work, and the concepts of credibility, legitimacy, saliency and capacity development, extremely useful for evaluating and improving the scenarios processes at the regional level. 
Open Access This article is distributed under the terms of the Creative Commons Attribution License which permits any use, distribution, and reproduction in any medium, provided the original author(s) and the source are credited.

\section{References}

Alcamo J (2008) The SAS approach: combining qualitative and quantitative knowledge in environmental scenarios. In: Alcamo J (ed) Environmental futures: the practice of environmental scenario analysis. Elsevier, Amsterdam

Cash DW, Clark WC, Alcock F, Dickson NM, Eckley N, Guston D, Jäger J, Mitchell R (2003) Knowledge systems for sustainable development. Proc Nat Acad Sci USA 100(14):8086-8091

Cash DW, Adger WN, Berkes F, Garden P, Lebel L, Olsson P, Pritchard L, Young O (2006) Scale and cross-scale dynamics: governance and information in a multilevel world. Ecol Soc 11(2): 12

Clark W, Tomich TP, van Noordwijk M, Dickson NM, Catacutan D, Guston D, McNie E. (2010) Toward a general theory of boundary work: insights from the CGIARG's natural resource management programs. Center for international development working paper 199

Clark W, Tomich T, van Noordwijk M, Gustond D, Catacutan D, Dickson NM, McNief E (2011) Boundary work for sustainable development: natural resource management at the consultative group on international agricultural research (CGIAR). PNAS. doi:10.1073/pnas.0900231108

Ericksen PJ (2008) What is the vulnerability of a food system to global environmental change? Ecol Soc 13(2):14. http://www. ecologyandsociety.org/vol13/iss2/art14/

Food and Agriculture Organization of the United Nations (2009) How to feed the world in 2050. High level expert forum. http://www. fao.org/fileadmin/templates/wsfs/docs/expert_paper/How_to_ Feed_the_World_in_2050.pdf

Fujimura J (1992) In: Pickering A (ed) Crafting science: standardized packages, boundary objects, and "translation" in science as culture and practice. University of Chicago Press, Chicago

Gallopin GC (2002) Planning for resilience: scenarios, surprises, and branch points. In: Gunderson LH, Holling CS (eds) Panarchy: understanding transformations in systems of humans and nature. Island Press, Washington, DC

Guston DH (2001) Boundary organizations in environmental policy and science: an introduction. Sci Technol Human Values 26:399

Henrichs T, Zurek M, Eickhout B, Kok K, Raudsepp-Hearne C, Ribeiro T, van Vuuren D, Volkery A (2010) Scenario development and analysis for forward-looking ecosystem assessments. In: Ash N, Blanco H, Brown C, Garcia K, Henrichs T, Lucas N, Raudsepp-Hearne C, Simpson RD, Scholes R, Tomich TP, Vira B, Zurek M (eds) Ecosystems and human well-being. A manual for assessment practitioners. Island Press, Washington, DC

Huitema D, Turnhout E (2009) Working at the science-policy interface: a discursive analysis of boundary work at the Netherlands Environmental Assessment Agency. Environ Politics 18(4):576-594

Jasanoff S (1996) Beyond epistemology: relativism and engagement in the politics of science. Soc Stud Sci 26:393-418

Jasanoff S (2003) Accounting for expertise. Sci Public Policy 30:157-162

Jones N, Jones H, Walsh C (2008) Political science? Strengthening science policy dialogue in developing countries. Overseas Development Institute Working Paper 294

Kahane AM (2010) Power and love: a theory and practice of social change. Berret-Koehler, San Francisco, USA
Kahn H, Wiener AJ (1967) The year 2000 a framework for speculation on the next thirty-three years. Macmillan, New York

Kok K, van Delden H (2004) Linking narrative storylines and quantitative models to combat desertification in the Guadalentín, Spain. In: iEMSs 2004 international congress: "Complexity and Integrated Resources Management”. International Environmental Modelling and Software Society

Kristjanson P, Reid R, Dickson N, Clark WC, Romney D, Puskur R, MacMillan S, Grace D (2009) Linking international agricultural research knowledge with action for sustainable development. Proc Natl Acad Sci USA 9(13):5047-5052

Leach M, Scoones I (2006) The slow race: making technology work for the poor. Demos, London

Liverman D, Ingram J (2010) Why regions? In: Ingram J, Ericksen P, Liverman D (eds) Food security and global environmental change. Earthscan, London, Washington, DC

Lucas N, Raudsepp-Hearne C, Blanco H (2010) Stakeholder participation, governance, communication, and outreach. In: Ash N, Blanco H, Brown C, Garcia K, Henrichs T, Lucas N, RaudseppHearne C, Simpson RD, Scholes R, Tomich TP, Vira B, Zurek M (eds) Ecosystems and human well-being. A manual for assessment practitioners. Island Press, Washington, DC

Reid RS, Nkedianye D, Said MY, Kaelo D, Neselle M, Makui O, Onetu L, Kiruswa S, Ole Kamuaro N, Kristjanson P, Burnsilver SB, Goldman M, Boone RB, Dickson NM, Clark WC (2009) Evolution of models to support community and policy action with science: balancing pastoral livelihoods and wildlife conservation in savannas of East Africa. Proc Natl Acad Sci USA. doi:10.1073/pnas.0900313106

Rittel HWJ, Webber MM (1973) Dilemmas in a general theory of planning. Policy Sci 4(2):155-169

Rotmans J, Van Asselt M, Anastasi C, Greeuw S, Mellors J, Peters S, Rothman D, Rijkens N (2000) Visions for a sustainable Europe. Futures 32(9):809-831. doi:10.1016/S0016-3287(00)00033-1

Schwartz PP (1991) The art of the long view: planning for the future in an uncertain world. Currency Doubleday, New York

Selsky J, McCann J (2008) Business planning in turbulent times: new methods for applying scenarios. Earthscan, London

van der Heijden K (1996) The art of strategic conversation. Wiley, New York

van Noordwijk M, Tomich TP, Verbis B (2001) Negotiation support models for integrated natural resource management in tropical forest margins. Conserv Ecol 2:5-21. http://www.consecol.org/ vol5/iss $2 / \operatorname{art} 21$

Van Notten PWF (2003) An updated scenario typology. Futures 35(5):423

Van Notten PWF, Sleegers AM, Van Asselt MBA (2005) The future shocks: on discontinuity and scenario development. Technol Forecast Soc Chang 72(2):175-194

Vermeulen SJ, Aggarwal PK, Ainslie A, Angelone C, Campbell B, Challinor AJ, Hansen J, Ingram J, Jarvis A, Kristjanson P, Lau C, Nelson G, Thornton PK, Wollenberg EK (2010) Agriculture, food security and climate change: outlook for knowledge, tools and action. Climate change, agriculture and food security report no. 3. http://www.ccafs.cgiar.org/resources

Vermeulen SJ, Aggarwal PK, Ainslie A, Angelone C, Campbell B, Challinor AJ, Hansen J, Ingram J, Jarvis A, Kristjanson P, Lau C, Nelson G, Thornton PK, Wollenberg EK (2011) Options for support to agriculture and food security under climate change. Environ Sci Policy. doi:10.1016/j.envsci.2011.09.003

Wilkinson A, Eidinow E (2008) Evolving practices in environmental scenarios: a new scenario typology. Environ Res Lett 3:1-11

Xiang WN, Clarke KC (2003) The use of scenarios in land-use planning. Environ Plann B Plann Des 30(6):885-909 